\title{
ScholarOne and Web of Science: Preeminent submission, peer review and indexation
}

Sigmar de Mello Rode Scientific Editor
Drazilian Oral Research (BOR) has been undergoing constant and sweeping changes in its present management, striving to improve visibility and functionality. With this in mind, we changed its publication frequency from quarterly to bimonthly; we adopted the publication of articles Abead of Print; we expanded our indexation in several databases, and we diversified the genre of articles published, among other changes.

Now we have two more important developments to report.

The first is related to the processing of articles. Some years ago, an editorial decision dictated that we would not adopt one of the electronic submission systems made available by the Scientific Electronic Library Online (SciELO), because we believed it had some operational limitations. We decided to wait until SciELO implemented ScholarOne, a submission and management system used by most of the international journals. Accordingly, we decided to maintain our traditional submission system (via email) until such time as a system that better met our needs would be made available. We now take great pleasure in announcing that we will be the $10^{\text {th }}$ journal in the SciELO database to implement electronic submission and peer-review using the ScholarOne system.

Starting November 1, 2012, the entire article submission and evaluation process will be conducted exclusively through ScholarOne, after some months of training and adaptation. ScholarOne is provided free of charge by ScieELO to the journals indexed in its database. This system makes the manuscript submission and evaluation process easier and speedier, by allowing interested parties to follow and participate in the stages of manuscript submission and processing by logging directly into the system, participating in each different stage and following the process through automatic reports and notification received via Internet.

The second - and undoubtedly most important - development is that we were invited to join Thomson Reuter's Science Citation Index - Expanded on the Web of Science and Web of Knowledge as of Volume 25 (2011) of our journal. Following the footsteps of the Journal of Applied Oral Science (JAOS), we will thus be the second Brazilian dentistry journal to join this important database and enjoy an impact factor ranked and announced by this organization.

These two novelties will greatly increase the visibility of BOR and of its published articles. This, in turn, is expected to increase the number of articles submitted and will, consequently, call for greater rigor in evaluating the articles. Accordingly, we will be increasing the number of non-Brazilian peer-reviewers.

However, we don't expect to stop here. We are already making the needed adjustments to BOR so that its articles conform to the system adopted by PubMed Central, in order to allow quicker indexation in this important database of the National Institutes of Health's National Library of Medicine (NIH/NLM). We will also continue to pursue an A rating in the Qualis qualification system of CAPES. All this is targeted to boost the internationalization of our journal.

We still have a long and hard road ahead of us, but the advances that we have already achieved attest to the fact that we have spared no pains to attain our goal of disseminating the scientific excellence of Brazilian and world dentistry on the pages of the BOR. Your participation and your support are fundamental to make this happen. 